\title{
Intravascular Ultrasound Evaluation of Equivocal Angiographic Imaging During Percutaneous Coronary Intervention of Bifurcation Lesions
}

\author{
Arturo R. Quizhpe ${ }^{1}$, Carlos Ortega², Diego Carrión Monsalve³, María Fernanda González4, \\ María Augusta Córdova ${ }^{5}$, Juan Vintimilla Garate ${ }^{6}$, Maritza Siguenza $^{7}$
}

\begin{abstract}
The use of intravascular ultrasound (IVUS) to guide stent implantation in bifurcation lesions, especially for the detection of procedure-related complications, has decreased the rates of major clinical outcomes. We report a case of a patient undergoing bifurcation intervention, where the guidewire inadvertently was passed behind the proximal stent struts, deforming the stent edge. This complication was suspected at the angiography and was confirmed by IVUS. IVUS was crucial for the diagnosis, to confirm the correct repositioning of the guidewire, and to assess the optimal expansion and complete apposition of stent struts, thus preventing a possible early thrombotic event and ensuring a good long-term outcome.
\end{abstract}

DESCRIPTORS: Coronary stenosis. Ultrasonography, interventional. Angioplasty. Stents. Coronary angiography.
C oronary lesions located within bifurcations represent $20 \%$ of percutaneous coronary interventions ( $\mathrm{PCls}$ ) and provide both a clinical and a technical challenge, as the procedure has a low rate of angiographic success, a high number of complications, and a high chance of restenosis and late thrombosis. ${ }^{1}$ Incomplete apposition and inadequate expansion of drug-eluting stents (DES) have been associated with an increased

\section{RESUMO}

\section{Avaliação Ultrassonográfica Intracoronária de Imagem Angiográfica Duvidosa Durante Intervenção Percutânea em Bifurcação}

O uso do ultrassom intracoronário (USIC) para guiar o implante do stent em bifurcações, especialmente na detecção de complicações relacionadas ao procedimento, tem diminuído as taxas de desfechos clínicos maiores. Neste artigo, reportamos o caso de um paciente submetido a intervenção em bifurcação, em que o fio-guia ultrapassou inadvertidamente por trás das hastes proximais do stent, levando à deformação de sua borda. A complicação foi suspeitada na angiografia e confirmada com o USIC. O USIC foi fundamental no diagnóstico, na confirmação do reposicionamento correto do fio-guia, e na avaliação da ótima expansão e da aposição completa das hastes do stent, prevenindo possível desfecho trombótico precoce e garantindo o resultado a longo prazo.

DESCRITORES: Estenose coronária. Ultrassonografia de intervenção. Angioplastia. Stents. Angiografia coronária.

risk of early and late thrombosis, which result in high morbidity and mortality rates. ${ }^{2}$

The difference between the diameters of the main vessel and the lateral branch usually causes malapposition of the proximal stent segment immediately after implantation, which must be corrected by post-dilatation using the kissing balloon technique or inflating a short

\footnotetext{
1 Physician; Interventional cardiologist at the Hospital José Carrasco Arteaga Hemodynamics Unit. Cuenca, Ecuador.

2 Physician; Cardiologist at the Hospital José Carrasco Arteaga Cardiology Service. Cuenca, Ecuador.

${ }^{3}$ Medical Intern at the Hospital José Carrasco Arteaga Internal Medicine Clinic. Cuenca, Ecuador.

${ }^{4}$ Physician at the Hospital Santa Inés. Cuenca, Ecuador Hemodynamics Unit.

${ }^{5}$ Physician; Cardiologist and echocardiographist at the Hospital Santa Inés. Cuenca, Ecuador Cardiology Service.
}

\footnotetext{
${ }^{6}$ Physician; Cardiologist and echocardiographist at the Hospital José Carrasco Arteaga. Cuenca, Ecuador Cardiology Service.

7 Imaging specialist at the Hospital José Carrasco Arteaga. Cuenca, Ecuador Hemodynamics Unit.
}

Correspondence to: Arturo R. Quizhpe. Hospital José Carrasco Arteaga. Rayoloma y Popayan - Cuenca, Ecuador

E-mail: riquizimo@yahoo.es

Received on: 4/2/2012 • Accepted on: 07/30/2012 
balloon with the main vessel diameter (proximal optimisation technique).

The use of intravascular ultrasound (IVUS) has helped overcome several angiography limitations. For bifurcation intervention evaluation, IVUS allows for the determination of the atherosclerotic plaque characteristics and the selection of the best treatment, as well as optimisation of the expansion and apposition of stent struts. ${ }^{3}$

The present study reports the case of a patient who had $\mathrm{PCl}$ in bifurcations during a drug-eluting stent implantation that was assessed by IVUS due to the presence of an equivocal image during the procedure.

\section{CASE REPORT}

A 56-year-old male patient was transferred from a community hospital due to typical chest pain that lasted for 24 hours at rest and was associated with electrocardiogram alterations (sinus rhythm and symmetric inversion of the $\mathrm{T}$ wave in $\mathrm{V} 1$ to $\mathrm{V} 5$ ). He was treated with $100 \mathrm{mg}$ aspirin, an initial dose of $600 \mathrm{mg}$ clopidogrel and $75 \mathrm{mg}$ maintenance doses, $20 \mathrm{mg}$ simvastatin, 25 $\mathrm{mg}$ atenolol, and $70 \mathrm{mg}$ enoxaparin every 12 hours.

Based on the findings, a decision was made to perform invasive risk stratification by coronary angiography.

\section{Coronary angiography}

The left anterior descending artery had $80 \%$ lesions in the proximal third with an image that suggested intracoronary thrombus at the first diagonal branch bifurcation. Importantly, the diagonal branch demonstrated no significant atherosclerotic lesions (Figure 1A). The left circumflex and right coronary arteries demonstrated mild diffuse parietal irregularities.

\section{Procedure}

Vascular access was obtained radially, followed by EBU 3.5 6-F guide-catheter positioning at the left coronary trunk origin. An intracoronary tirofiban bolus was administered. The 0014 PT Graphix guidewire was advanced past the lesion and placed in the distal segment of the left anterior descending artery, and another Choice floppy guidewire was introduced in the diagonal branch. A 3.5 × $33 \mathrm{~mm}$ Cypher $^{\mathrm{TM}}$ stent (Cordis - Miami, USA) was implanted in the left anterior descending artery in crossover with the diagonal branch (Figure 1B) and released at 9 atm. Post-implantation angiographic control demonstrated Thrombolysis In Myocardial Infarction (TIMI) III flow, a smaller proximal stent diameter than the proximal reference of the left anterior descending artery, a diagonal branch with a $90 \%$ lesion at its origin, and an image that suggested an intracoronary thrombus that was most likely displaced from the left anterior descending artery. Post-dilation was used simultaneously with the kissing balloon technique and proximal optimisation
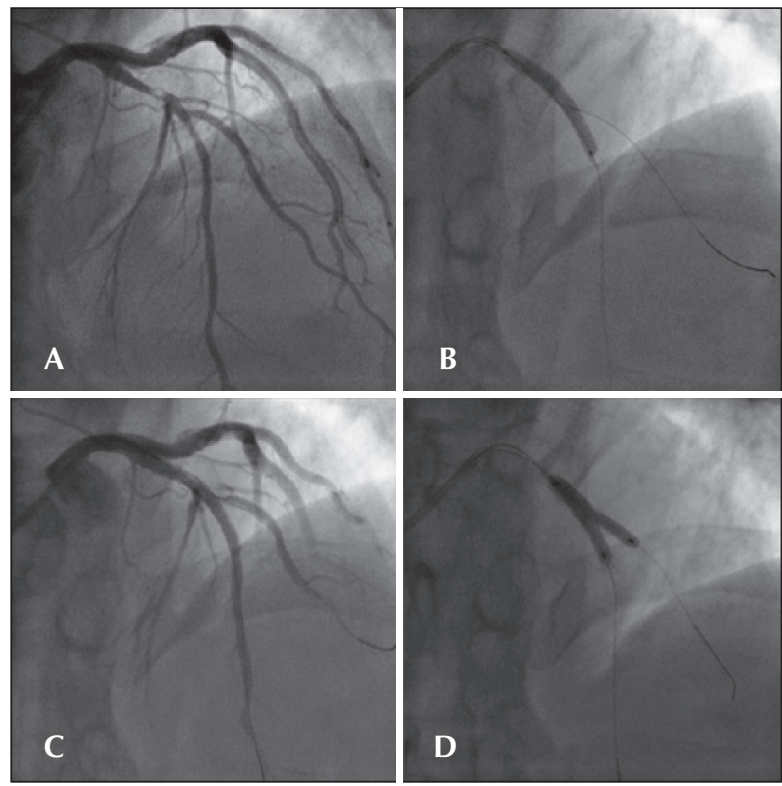

Figure 1 - In A, the initial angiogram demonstrating 80\% lesion in the left anterior descending artery with an image that is suggestive of intracoronary thrombus. In B, Cypher ${ }^{\mathrm{TM}} 3.5 \times 33 \mathrm{~mm}$ stenting with guidewire to protect the lateral branch. In $\mathrm{C}$, angiographic contro immediately after implantation demonstrating severe injury to the diagonal branch origin. In D, post-dilation with kissing balloon.

aiming to correct the proximal stent diameter and improve residual diagonal branch stenosis. Before post-dilation, the left anterior descending artery guidewire was pulled up to the origin of the diagonal branch and advanced through the stent struts, easily reaching the middle third of this vessel. The diagonal branch guidewire was then retreated to the guide catheter interior, reintroduced into the left anterior descending artery through the already implanted stent lumen, and advanced to the distal third of the artery (Figure 1C).

After performing the kissing balloon technique with a Sequent $3 \times 20 \mathrm{~mm}$ balloon that was inflated to $12 \mathrm{~atm}$ in the left anterior descending artery, and a Sequent $3 \times 20 \mathrm{~mm}$ balloon that was inflated to $10 \mathrm{~atm}$ and directed to the diagonal branch (Fig. 1 D), dilatation of the proximal third of the stent was performed with a Quantum $4 \times 12 \mathrm{~mm}$ balloon at $12 \mathrm{~atm}$. The guidewire in the diagonal branch was retreated and the final angiographic control was performed. However, an equivocal image (haziness) was observed in the proximal stent border, thus IVUS was performed (Figure 2). IVUS demonstrated strut deformity in the proximal stent border with the IVUS catheter positioned outside the stent lumen. The guidewire was also outside the stent lumen in its proximal border (Figure $3 \mathrm{~A}$ and B). This guidewire was left in the same position, and another guidewire was advanced through the crushed struts followed by a new IVUS evaluation, which confirmed its correct position (Figures $3 \mathrm{C}$ and $\mathrm{D}$ ). 

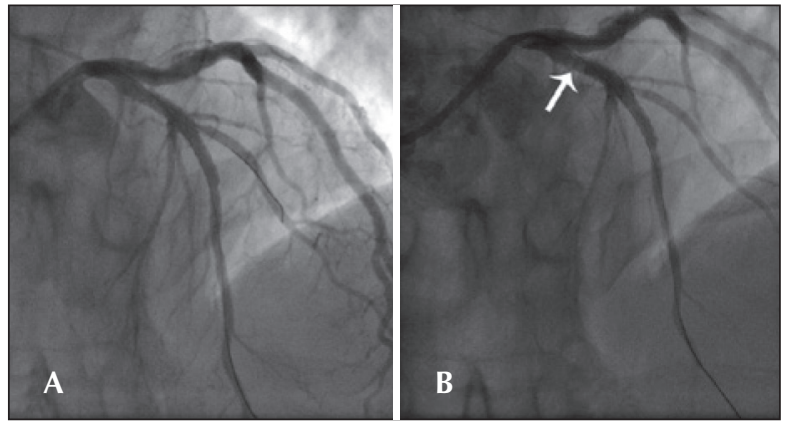

Figure 2 - In A, angiographic control after the kissing balloon. In B, final angiographic control without the guidewire in the diagonal branch demonstrating an equivocal image in proximal stent border (arrow).
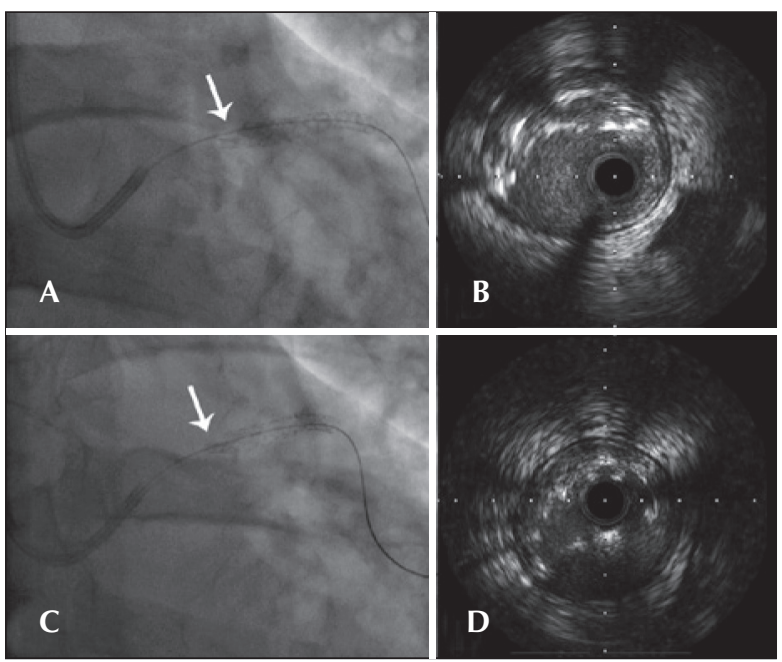

Figure 3 - In A, angiography demonstrating the guidewire behind the proximal stent struts (arrow). In B, IVUS demonstrating the catheter outside the stent lumen. In C, angiography immediately after passage of a new guidewire inside the crushed struts (arrow). In D, IVUS demonstrating the correct guidewire position.

With the guide wire inside the stent, a new postdilation was performed with a noncompliant Quantum $4 \times 12 \mathrm{~mm}$ balloon at $12 \mathrm{~atm}$. The IVUS performed at that time revealed proximal border dissection, and it was chosen to implant a new Cypher ${ }^{\mathrm{TM}} 3.5 \times 13 \mathrm{~mm}$ stent at $18 \mathrm{~atm}$ in the proximal border. The final IVUS evaluation demonstrated favorable outcome without left anterior descending artery lesions (Figure 4).

The patient recovered uneventfully after the $\mathrm{PCl}$, was discharged, and is currently asymptomatic.

\section{DISCUSSION}

$\mathrm{PCls}$ within bifurcations are independent predictors of stent thrombosis and are associated with catastrophic clinical consequences, mortality in $20 \%$ to $48 \%$ of cases, and stroke in $60 \%$ to $70 \%$ of cases. ${ }^{4}$ Stent thrombosis

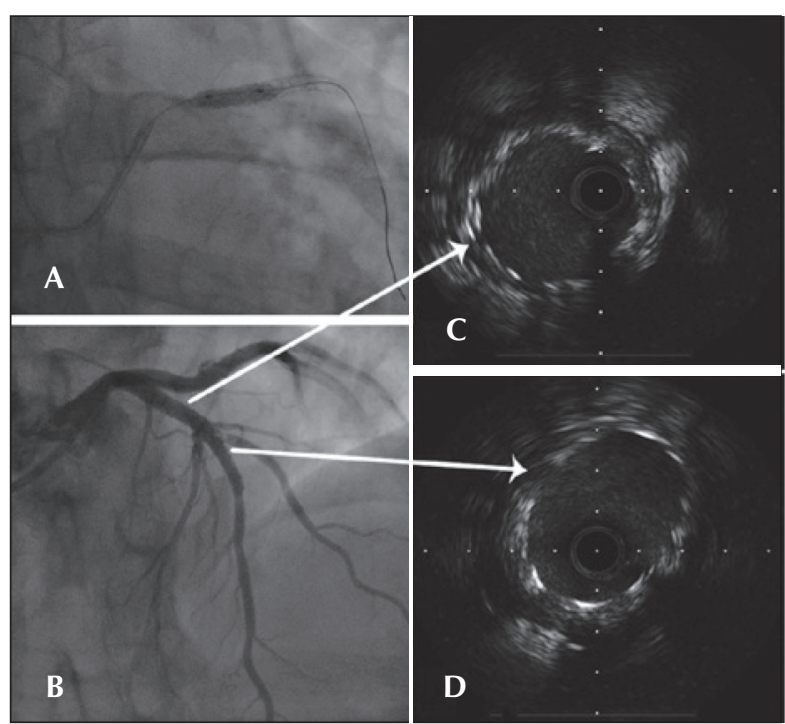

Figure 4 - In A, second Cypher ${ }^{\mathrm{TM}}$ stent implantation to correct the dissection of the proximal border of the first stent. In B, IVUS demonstrating good expansion and complete strut apposition at the overlap site. In C, final angiographic control. In D, IVUS of the left anterior descending artery at the bifurcation site.

is a complex process that results from the interaction of factors that are related to the patient, the lesion, the implanted device, and the technique used. The provisional stent strategy of the lateral branch is employed in over $80 \%$ of bifurcations and is associated with low stent thrombosis rates. However, if the lateral branch is thickened with an atherosclerotic lesion that extends beyond $5 \mathrm{~mm}$ from the origin, a two stent implanting strategy becomes necessary, although the best technique has yet to be established. ${ }^{5}$

This case had a lesion type of 1,1,0 (Medina classification) with $<70$-degree angle, main vessel proximal reference diameter of $3.2 \mathrm{~mm}$, distal reference diameter of $2.7 \mathrm{~mm}$ and lateral vessel diameter of $2.2 \mathrm{~mm}$. The provisional T-stenting strategy was chosen, with stent deployment at low pressure to respect the distal reference vessel page. Because of the possibility of malapposition of the proximal stent segment and the need to correct the severe lateral branch lesion, postdilation with simultaneous kissing balloon and proximal optimisation techniques were employed.

The main vessel in its proximal segment has a systematically larger diameter than its distal segment at the lateral branch origin, which is more pronounced the greater the diameter of the distal reference vessel is. ${ }^{6}$ Soon after stent implantation, incomplete strut apposition occurred in the proximal segment, which led to the inadvertent retreat of the guidewire to behind the first stent struts from the lateral branch. Although the guidewire is routinely removed from the lateral branch to the guide catheter interior, the guidewire 
passage occurred between the vessel wall and the stent proximal segment.

There are two methods to optimize the proximal stent diameter in bifurcations. The first is the proximal optimisation method, in which a hypersized short balloon is insufflated proximal to the carina, thus achieving localized stent expansion, which allows for movement past the lateral vessel more easily. The second method is to use the simultaneous kissing balloon, wherein balloon insufflation will treat the lateral branch lesion simultaneously to achieve complete apposition of the proximal stent struts. ${ }^{7}$ The technical limitation of this proximal malapposition correction technique is that it increases procedure complexity, thus causing elliptical stent expansion and facilitating the inadvertent guidewire passage behind the stent struts. In addition, the routine use of the final kissing balloon technique has been questioned by the Nordic-Baltic Bifurcation Study III (NORDIC III), where its benefit was demonstrated only in cases of true bifurcation lesion treatment, for the purpose of reducing lateral branch restenosis, and maintaining a rate of major clinical events similar to that of the group who had not undergone the technique. ${ }^{7}$

In the present case, the lateral branch demonstrated no initial lesion; soon after stent implantation there was plaque displacement with thrombus toward its ostium, which led to simultaneous post-dilation performance.

One way to prevent the occurrence would have been to employ the proximal stent optimisation technique. However, according to lakovou et al., ${ }^{8}$ the main vessel stent should be released at low pressure to avoid damaging the jailed guidewire or deteriorating the lateral branch origin, and the guidewires should be replaced to perform the proximal segment optimisation technique and subsequently use the kissing balloon, if necessary.

The advantages of using IVUS as a guide during bifurcation angioplasty include information on the plaque distribution and composition, determination of the stent diameter and length, evaluation of stem expansion and apposition, and detection of complications such as dissected borders. These factors may influence major clinical outcomes. A study by Kim et al. ${ }^{3}$ evaluated 758 patients undergoing bifurcation $\mathrm{PCl}$, excluding those of the left main coronary artery, and compared 473 IVUS-guided patients to 285 patients treated without this technique. At the four-year follow-up, patients in the IVUS-guided group had lower mortality and very late thrombosis rates, but there was no effect on target lesion revascularisation.

The use of IVUS in the present case was very important, as it helped detect proximal stent deformation and assess the correct location of the new guidewire for post-dilatation and second stent implantation. Additionally, the final outcome was assessed by IVUS to determine whether there was good expansion and complete stent strut apposition. Although some studies have demonstrated a decreased mortality rate, a decreased stroke rate, and less need for a revascularisation in patients undergoing bifurcation lesion PCls, it is important to wait for clinical trials that are designed for this purpose, so that the routine IVUS use can be recommended in all bifurcation cases., ${ }^{3,9}$

New imaging techniques with higher resolution than IVUS are available for atherosclerotic bifurcation disease assessment, such as optical coherence tomography, which could offer greater diagnostic precision of incomplete apposition and late stent thrombosis risk predictors. ${ }^{10}$ However, there are limitations, such as the low availability at cardiac catheterisation units as well as the associated costs. Another possibility for bifurcation treatment is the use of fractional myocardial flow reserve in the lateral branch functional assessment and intervention requirement. The understanding that the angiographic assessment overestimates jailed vessel severity could decrease lateral branch stenting. ${ }^{11}$

This case demonstrates an infrequent complication in bifurcation treatment, which reflects a need for the surgeon to recall the anatomical and technical principles of this complex subgroup. This case also highlights a role for IVUS in the diagnosis of equivocal angiographic images and as a guide during complex procedures, in order to ensure good results in the short- and long-term.

\section{CONFLICTS OF INTEREST}

The authors declare no conflicts of interest.

\section{REFERENCES}

1. Colombo A, Moses JW, Morice MC, Ludwig J, Holmes DR Jr, Spanos V, et al. Randomized study to evaluate sirolimus-eluting stents implanted at coronary bifurcations lesions. Circulation. 2004;109(10):1244-9.

2. Okabe T, Mintz GS, Buch AN, Roy P, Hong YJ, Smith KA, et al. Intravascular ultrasound parameters associated with stent thrombosis after drug-eluting stent deployment. Am J Cardiol. 2007;100(4):615-20.

3. Kim SH, Kim YH, Kang SJ, Park DW, Lee SW, Lee CW, et al. Long-term outcomes of intravascular ultrasound-guided stenting in coronary bifurcation lesions. Am J Cardiol. 2010;106(5): 612-8.

4. Iakovou I. Thrombosis after stent implantation: how much of a problem is there?. Future Cardiol. 2008;4(3):261-7.

5. Hildick-Smith D, Lassen JF, Albeiro R, Lefevre T, Darremont $\mathrm{O}$, Pan $\mathrm{M}$, et al. Consensus from the $5^{\text {th }}$ European Bifurcation Club meeting. Eurolntervention. 2010;6(1):34-8.

6. Finet G, Gilard M, Perrenot B, Rioufol G, Motreff P, Gavit $\mathrm{L}$, et al. Fractal geometry of arterial coronary bifurcation: a quantitative coronary angiography and intravascular ultrasound analysis. Eurolntervention. 2008;3(1):10-7.

7. Niemela M, Kervinen K, Erglis A, Holm NR, Maeng M, Christiansen $\mathrm{EH}$, et al. Randomized comparison of final kissing balloon dilatation versus no final kissing balloon dilatation in patients with coronary bifurcation lesions treated with main vessel stenting. NORDIC III. Circulation. $2011 ; 123(1): 79-86$. 
8. lakovou I, Ge L, Colombo A. Contemporary stent treatment of coronary bifurcations. J Am Coll Cardiol. 2005;46(8): 1446-55.

9. Patel Y, Depta J, Novak E, Yeung M, Lavine K, Banerjee S, et al. Long-term outcomes with use of intravascular ultrasound for the treatment of coronary bifurcation lesions. Am J Cardiol. 2012;109(7):960-5.
10. Ferrante G, Kaplan AV, Di Mario C. Assessment with optical coherence tomography of a new strategy for bifurcation lesion treatment: the Tryton Side-Branch-Stent. Catheter Cardiovasc Interv. 2009;73(1):69-72.

11. Koo BK, Kang HJ, Youn TJ, Chae IH, Choi DJ, Kim HS, et al. Physiological assessment of jailed side branch lesions using fractional flow reserve. J Am Coll Cardiol. 2005;46(4): 633-7. 